\title{
Negociações Comerciais Internacionais e Democracia: 0 Contencioso Brasil x EUA das Patentes Farmacêuticas na OMC
}

\author{
Marcelo Fernandes de Oliveira \\ Fernanda Venceslau Moreno
}

\section{INTRODUÇÃO}

( ) s objetivos deste artigo são: a) apresentar breve discussão teórica sobre a interação entre os níveis doméstico e internacional durante processos de negociações internacionais, tendo como base o Jogo de Dois Níveis - JDN, de Putnam (1993), complementado por Milner (1997); b) efetuar uma análise comparativa das instituições políticas democráticas relevantes no processo de formulação da tomada de decisões em questões internacionais dos Estados Unidos e do Brasil; c) demonstrar a viabilidade analítica dessa análise no contencioso Brasil $x$ EUA das patentes farmacêuticas na Organização Mundial do Comércio-OMC; e, por fim, d) apontar que, no âmbito da OMC, países de menor poder relativo podem ser capazes de obter ganhos contra as principais potências da sociedade internacional contemporânea. Para alcançar estes objetivos, será analisada a formação das estruturas domésticas de ganhos de cada país que sustentaram suas respectivas posições na OMC em torno da questão. Finalmente, serão avaliadas as condições que levaram uma opção de política pública brasileira a afetar a configuração do Agreement on Trade-Related Aspects of Intellectual Property Rights (TRIPS) na arena internacional.

O estudo empírico realizado à luz do JDN e da perspectiva comparativa parece sugerir que uma maior abertura e a institucionalização do re-

DADOS - Revista de Ciências Sociais, Rio de Janeiro, Vol. 50, nº-1, 2007, pp. 189 a 220. 
lacionamento entre policy-makers e atores das organizações da sociedade civil - tal como ocorre nos Estados Unidos através do United States Trade Representative (USTR) - podem possibilitar um melhor atendimento às demandas da sociedade brasileira, aperfeiçoando a qualidade técnica da negociação e contribuindo para a democratização da construção do interesse nacional a ser defendido no exterior pela diplomacia brasileira. Nesse sentido, elas poderiam tanto gerar maior credibilidade, conferindo legitimidade internacional às ações do país no exterior, quanto servir de base para uma reflexão sobre como construir instituições democráticas para a formulação da política externa no país.

\section{NEGOCIAÇÕES INTERNACIONAIS E DEMOCRACIA: QUESTÕES TEÓRICAS}

Este artigo visa compreender a formulação da posição negociadora dos Estados Unidos e do Brasil durante o contencioso na OMC em torno da legalidade do uso de licença compulsória ${ }^{1}$ para a produção de medicamentos necessários para o tratamento de doentes brasileiros de HIV/AIDS vis-à-vis o Acordo TRIPS. Trata-se de um contencioso que ilustra o aumento, sem precedentes, da interação entre políticas domésticas e o contexto internacional na contemporaneidade, já que, pela primeira vez, uma política pública de saúde de um país periférico foi contestada em uma organização internacional. Para subsidiar este estudo, escolhemos como suporte teórico o JDN, de Putnam (1993), complementado pela análise de Milner (1997).

Putnam (1993) afirma que existe uma profunda relação entre a escolha pela cooperação realizada pelos governos no plano internacional e os interesses domésticos que eles representam. Ou seja, a cooperação pode avançar, sofrer limites ou mesmo refluir, dependendo da capacidade de poder de veto ou do apoio dos atores domésticos identificados com a questão em negociação. O governante ou negociador internacional (statesman) sofre pressões dos grupos de interesse domésticos, que têm preferências distintas. Assim, o "interesse nacional" não é definido de maneira exclusiva pelo poder central (Executivo), mas deriva também do debate interno entre os diversos poderes (Legislativo, Executivo e Judiciário), os grupos de interesse e a opinião pública, dentre outros. Nessa lógica, o Estado não é considerado um ator único, e as decisões são tomadas em um ambiente poliárquico. 
É por isso que Putnam denomina seu modelo teórico de JDN, pois nele os governos responsáveis pela política externa dos estados, considerados como negociadores internacionais, atuam junto aos seus interlocutores domésticos, com os quais negociam a ratificação e entrada em vigor dos acordos - daí a importância do papel dos atores políticos e do nível de pressão que estes sofrem por parte dos grupos de interesses econômicos e sociais que os apóiam -, e, simultaneamente, agem no plano internacional, no qual negociam (jogam) em busca da cooperação com outros estados.

"No âmbito nacional, os grupos domésticos buscam seus interesses pressionando o governo a adotar políticas favoráveis, e os políticos buscam o poder por meio de construção de coalizões entre esses grupos. No âmbito internacional, os governos nacionais procuram maximizar sua própria habilidade de satisfazer as pressões domésticas, enquanto minimizam as conseqüências adversas de efeitos externos. Nenhum dos dois jogos podem ser ignorados pelos principais tomadores de decisões, enquanto seus países remanecerem interdependentes, porém com soberania" (Putnam, 1993:436, tradução dos autores).

Vale ressaltar aqui que no JDN há dois momentos específicos: a negociação internacional e a ratificação do acordo internacional no plano doméstico.

A cooperação, portanto, será mais ou menos provável dependendo de quão atraente seja uma determinada política para os grupos de interesse. A razão para isso é que o interesse dos grupos em uma dada política afetará a maneira como os políticos enxergam a questão, ou seja, se serão favoráveis ou contrários à sua ratificação. "Aqueles que perdem devem bloquear ou tentar alterar qualquer acordo internacional, enquanto aqueles que se beneficiam devem pressionar para sua ratificação" (Milner, 1997:63, tradução dos autores).

Logo, é a dinâmica interna que definirá as possibilidades e as opções da ação internacional do Estado, e ela é determinada pela formulação e pela acomodação das preferências domésticas em coalizões políticas que podem ou não ser favoráveis à ratificação e implementação do acordo internacional. As preferências domésticas traduzidas em coalizões políticas que representam demandas junto ao Estado são denominadas por Putnam de win-set (estrutura de ganhos). Assim, podemos concluir que os resultados possíveis da busca por cooperação internacional são afetados pelo win-set de cada um dos negociadores. Geral- 
mente, o win-set é definido pelas Organizações Não-Governamentais ONGs, movimentos sociais, lobbies, partidos políticos, parlamentares e governos subnacionais, dentre outros.

Putnam (1993) argumenta que um governo dividido - ou seja, aquele no qual não há amplo consenso entre os interlocutores domésticos pode obter maior sucesso em acordos internacionais do que aquele que incorpora e representa um consenso doméstico mais amplo. Em outras palavras, por ocasião da negociação internacional, as dissensões internas são benéficas ao governo ao tornarem evidente aos seus parceiros nos acordos que, se estes não forem ao encontro do seu win-set, eles não serão ratificados no Parlamento. Portanto, quanto menor o win-set, ou ainda, quanto mais difusas forem as posições no âmbito doméstico, mais força terá o governo na negociação internacional. E quanto maior o win-set, maior será a possibilidade de se alcançar um acordo; em contrapartida, a capacidade de barganha do governo vis-à-vis outros negociadores é menor.

Isso significa que, para ser favorável a um determinado Estado, a negociação internacional não exige que haja consenso em torno dela, mas sim o contrário, porque, na medida em que haja mobilização doméstica e divisão de interesses em torno de assuntos de política externa, ao invés de o Estado enfraquecer-se, ele se torna mais poderoso, visto que de antemão fica claro que, se o acordo internacional for contrário aos interesses de grupos econômicos e sociais, ele não será ratificado no Parlamento e não poderá entrar na ordem constitucional do país.

O oposto também é verdadeiro. Uma negociação internacional que tenha sido amplamente discutida com a sociedade, uma vez aprovada, terá legitimidade democrática e portanto dificilmente será alterada. Em outras palavras, a discussão democrática da política externa com a sociedade garante credibilidade às negociações. Nesse sentido, a perda de agilidade negociadora para alcançar um acordo será recompensada pela credibilidade que ele obteve junto a sociedade, a qual, por ter sido previamente consultada e ter seus interesses contemplados, não contestará posteriormente o acordo celebrado (Martin, 2000).

Cabe assinalar, porém, que o uso desse argumento eleva o risco de que a negociação internacional não ocorra caso o win-set do outro negociador também não permita avanços, ampliando assim a possibilidade de defecção; ou seja, governos com menor win-set provavelmente têm poucas possibilidades de cooperar. Segundo Putnam, a defecção ocor- 
re quando o acordo internacional não é ratificado, não sendo portanto respeitado. Ela pode ser voluntária, quando o negociador deliberadamente decide não respeitar o acordo, ou involuntária, isto é, quando o negociador se torna incapaz e/ou impossibilitado de respeitá-lo por qualquer razão que foge ao seu controle.

Ao analisar essa questão, Milner (1997) conclui que a influência do nível doméstico nas negociações internacionais será definida pelo papel desempenhado pelas instituições políticas democráticas de cada Estado e pelos mecanismos de que elas dispõem para distribuir o poder durante a formulação e o processo de tomada de decisões da política externa, uma vez que a organização do Estado interfere nesse processo. Portanto, para Milner, "Instituições políticas domésticas determinam como o poder sobre o processo decisório é alocado entre os atores nacionais" (idem:99, tradução dos autores).

Logo, entender as relações institucionais em democracias, principalmente entre o Executivo e o Legislativo, é fundamental para a compreensão das negociações internacionais a partir do nível doméstico². "Variações ou mudanças nessa relação institucional influenciam a probabilidade e os termos da cooperação internacional" (ibidem, tradução dos autores).

Assim, é importante enfatizar que tanto o Brasil quanto os Estados Unidos são países democráticos, regidos por um sistema presidencial. Neles, as decisões não são concentradas única e exclusivamente no Poder Executivo; pelo contrário, espera-se que elas sejam tomadas em um ambiente poliárquico e divididas entre os poderes Executivo, Legislativo e Judiciário. Outra semelhança entre esses países é o fato de que ambos possuem um sistema bicameral, no qual o Parlamento se divide entre Senado e Congresso (veto players), que têm poder de vetar políticas internacionais previamente negociadas pelo Executivo. No entanto, é interessante frisar que, no Brasil, o Executivo tem a prerrogativa de legislar através de medidas provisórias ${ }^{3}$, o que não existe nos Estados Unidos, a não ser em casos muito raros e extremamente urgentes. Esta prerrogativa confere ao Executivo brasileiro um poder adicional para agir unilateralmente, criando legislação temporária sem o consentimento do Legislativo. Em termos comparativos, é possível afirmar que o poder se encontra mais concentrado no Executivo no Brasil do que nos Estados Unidos. 
Muitos autores concordam ao afirmar que em países da América Latina, incluindo o Brasil, o Estado tende a ser "forte" ${ }^{4}$, e as sociedades são normalmente "fracas". Uma das explicações para isso é o fato de que os estados tiveram que tomar para si a responsabilidade de fazer a economia crescer e de iniciar uma nova e competitiva atividade: a industrialização. Para isso, necessitavam ser fortes e concentrar muito poder (Rogowski, 1990). A idéia é que esses países, considerados "atrasados" (late comers), encontravam-se defasados em relação àqueles que haviam se industrializado há mais tempo. Na América Latina, para suprir essa deficiência, o Estado se tornou "forte", desempenhando o papel da iniciativa privada e algumas vezes até mesmo suprimindo a sociedade, que tende a ser passiva e a aguardar que ele tome as decisões por ela. Este raciocínio poderia explicar por que as sociedades de Estados com essas características não se envolvem mais ativamente com a política, sobretudo com a política externa.

Nos Estados Unidos, observa-se o inverso: a sociedade é considerada "forte" e o Estado, "fraco". A estrutura de governo do país é descentralizada, e o poder é dividido entre agências e escritórios que, algumas vezes, se sobrepõem uns aos outros. "Ele (Katzenstein) considerou os Estados Unidos, em contraste, com um Estado fraco e uma sociedade forte, na qual políticas foram caracterizadas pelo pluralismo social" (Evangelista, 1997:205, tradução dos autores). De acordo com Risse-Kappen (1990), os Estados mais "fracos" têm instituições políticas fragmentadas e estão mais abertos à pressão de grupos de interesse presentes na sociedade e nos partidos políticos (idem:484). Contudo, é necessário chamar a atenção para o fato de que, com a consolidação da democracia, a situação no Brasil vem se alterando. Como veremos na seção seguinte, os grupos de interesse domésticos estão paulatinamente se tornando mais ativos e envolvidos nas negociações internacionais, exercendo um papel cada vez mais importante nas questões relativas à política externa brasileira. Apesar disso, não se constataram modificações institucionais significativas no Ministério das Relações Exteriores capazes de absorver essas novas demandas. Quando ocorreram, elas parecem não ter sido suficientes.

Ainda nesse sentido, a necessidade de ratificação interna dos acordos assinados pelo Estado reforça a idéia de que, se estes não estiverem alinhados à preferência doméstica, não serão validados. O veto ou a ratificação, decididos pelo Parlamento, estão sujeitos à pressão interna exercida pelos lobbies. Alguns grupos de interesse têm maior capacida- 
de de influenciar as decisões do Estado e, portanto, de obter maior sucesso no seu objetivo de conduzir as negociações internacionais nos termos que lhes são mais favoráveis. "Grupos poderosos no âmbito de um país podem ser capazes de prevenir a adoção de políticas que eles não gostem de uma forma unilateral, mesmo que líderes políticos sejam favoráveis a elas" (Milner, 1997:73, tradução dos autores).

No Brasil e nos Estados Unidos, o Executivo é quem determina a agenda internacional (agenda-setter). A despeito desse poder, ele ainda depende do Legislativo (veto player) para traduzir seu "interesse" em políticas: "O Poder Executivo tem o poder de iniciar políticas vis-à-vis com outros países; o Poder Executivo pode criar uma agenda em política externa até um certo limite. Entretanto, para negociar acordos com países estrangeiros e implementar políticas externas, o Executivo geralmente precisa de um voto de confiança do Poder Legislativo" (ibidem, tradução dos autores).

No entanto, os poderes Executivo e Legislativo são compostos por políticos que, via de regra, desejam obter ou manter cargos públicos. Para isso, empenham-se em promover políticas que venham a incrementar suas possibilidades de eleição ou reeleição. Como veremos adiante, as políticas relacionadas ao tratamento do HIV / AIDS implementadas no Brasil visavam ao eleitor médio (median voter) e eram divulgadas como benéficas à população em geral, enquanto nos Estados Unidos a indústria farmacêutica era o alvo a ser favorecido pelas políticas públicas empregadas no país. No caso brasileiro, José Serra, ministro da Saúde à época, era candidato à Presidência da República; nos Estados Unidos, Bill Clinton, Al Gore - o candidato democrata -, mas principalmente George W. Bush, haviam sido financiados pelas indústrias farmacêuticas. Infelizmente, a pouca transparência no Brasil, no tocante ao financiamento das campanhas eleitorais, não nos permite efetuar o mesmo cruzamento de informações realizado no caso dos políticos norte-americanos. Na nossa opinião, o aperfeiçoamento da democracia brasileira também passa pela solução dessa problemática.

De um ponto de vista teórico, podemos afirmar que os laços entre policymakers no âmbito do Estado, atores políticos e grupos de interesse presentes na sociedade são indispensáveis, na medida em que podem tanto garantir maior poder de barganha ao negociador internacional, quanto debilitá-lo frente a uma negociação. Em outras palavras, governos que sofrem pressão interna de grupos de interesses identificados 
com assuntos de política externa dificilmente poderão estabelecer acordos internacionais que não sejam benéficos a esses grupos. Mas em países nos quais as dissensões domésticas não ocorrem ou são bloqueadas pelo insulamento da burocracia, é mais simples, durante a negociação internacional, um recuo nas suas posições, que poderá favorecer o negociador dividido. Este acaba usando "[...] a negociação internacional para consolidar sua posição política doméstica e, ao mesmo tempo, utilizar sua debilidade doméstica para extrair benefícios dos outros negociadores" (Veiga, 1999:38). Ou seja, um país em que as dissensões domésticas ocorrem mais freqüentemente, dentro de um marco institucional propício a elas, poderá ter vantagem sobre aqueles países que as inibem.

O Brasil faz parte desse segundo bloco de países; nele, os grupos de interesses não podem expressar claramente suas preferências no tocante à política externa ou vê-las traduzidas em pontos de veto no sistema político. Isso ocorre, em grande medida, devido à centralização da formulação da política externa no Ministério das Relações Exteriores MRE que, por seu insulamento burocrático - e sempre que exigido pelos parceiros -, pode recuar em suas posições em negociações internacionais cruciais para o país.

Logo, quando a política externa e, por extensão, os processos de negociação internacional se tornam assuntos de domínio público, sem mecanismos institucionais apropriados para o seu tratamento, como ocorre no Brasil, eles tendem a gerar profundas controvérsias na sociedade civil. Nesse sentido, ela passa a ser influenciada por uma ampla gama de atores econômicos, políticos e sociais que, muitas vezes, nem mesmo possuem interesses diretamente afetados pela questão em pauta, o que pode, de maneira desordenada, levar tanto ao estabelecimento de menor win-set, reforçando o poder do negociador internacional, quanto aumentar o win-set, diminuindo o poder em momentos indesejáveis. Ou seja, quando o win-set deveria ser menor, ele acaba se tornando maior - e vice-versa.

Conforme anteriormente mencionado, a situação no Brasil tende a mudar, tendo em vista não apenas uma maior atuação da sociedade civil em questões políticas, mas também o amadurecimento da democracia no país. Este pode ser notado através de uma maior mobilização da iniciativa privada, que crescentemente se tem utilizado de mecanismos como o lobby para ver suas demandas atendidas (De Bruns Neto, 2003). 
Figura 1

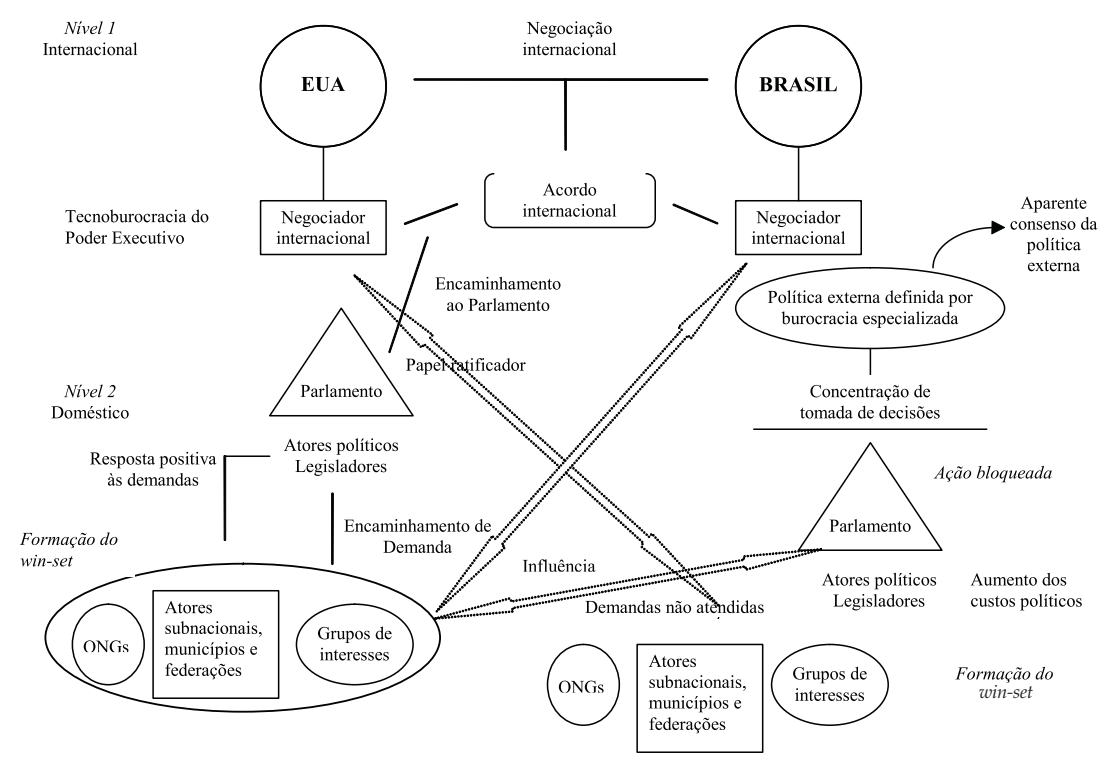

Fonte: Oliveira, 2005.

No caso do estudo analisado neste artigo, essa tendência à mudança aparece nitidamente. Contudo, como veremos nas considerações finais, ela ainda não está consolidada. Nesta perspectiva, e com base em tais pressupostos, analisaremos a seguir o comportamento adotado pelo Brasil e pelos Estados Unidos no contencioso relativo às patentes e à flexibilização do acordo TRIPS adotada naquela ocasião. Nesse sentido, demonstraremos na seção seguinte que a disputa em questão pode servir como exemplo de JDN.

\section{CONTENCIOSO BRASIL $x$ EUA DAS PATENTES NAS NEGOCIAÇÕES DA OMC}

A disputa acerca das patentes entre Brasil e Estados Unidos representou uma questão de grande relevância social e econômica. O governo brasileiro se opôs à indústria farmacêutica, sobretudo aos laboratórios estadunidenses, quando demandou o direito de passar por cima (override) da exclusividade de comercialização e/ou produção (market exclusivity) de medicamentos usados no tratamento de AIDS. Utilizan- 
do-se do argumento de que o bem-estar público deveria prevalecer sobre o lucro, o Brasil defendeu com firmeza sua posição.

O artigo 68 da Lei brasileira no 9.279/96 (que regula direitos e obrigações relativos à propriedade industrial) prevê a possibilidade do uso de licença compulsória em casos de emergência na saúde pública. A disputa teve início quando, em 2000, os Estados Unidos questionaram a utilização desse artigo pelo governo brasileiro, sob a alegação de que ele desrespeitava o acordo TRIPS. Assim, o Brasil foi inserido na Section 301 Watch List, acusado de ser "desrespeitador de patentes" (patentmiscreant). Em 30 de maio de 2000, os Estados Unidos entraram com pedido de consultas na OMC junto ao governo brasileiro. Não satisfeitos com a resposta brasileira e afirmando que as consultas não haviam produzido os resultados esperados - ou seja, a solução para o conflito -, em 9 de janeiro de 2001 entraram com pedido de estabelecimento de panel no Órgão de Solução de Controvérsias - OSC da OMC, apresentando a mesma queixa. Em junho de 2001, após diversas reuniões, negociações e consultas, os países chegaram a um acordo, considerado uma vitória brasileira: os Estados Unidos haviam admitido a possibilidade de quebra de patentes em questões de saúde pública de países em desenvolvimento. Por que o Brasil sagrou-se vitorioso na OMC no contencioso das patentes contra os Estados Unidos?

\section{Estrutura Doméstica e Posição Negociadora dos Estados Unidos}

A ameaça brasileira de permitir que laboratórios nacionais produzissem medicamentos genéricos ainda patenteados por laboratórios estadunidenses a preços mais baixos foi percebida pela indústria farmacêutica norte-americana como uma prática que poderia reduzir seus lucros no Brasil. Além disso, o setor temia que essa prática passasse a ser adotada por todos os países em desenvolvimento, colocando em risco os chamados "lucros extraordinários" (super profits) ${ }^{5}$. Para proteger seus interesses, a indústria farmacêutica estadunidense usou sua influência junto ao governo daquele país, exigindo que ele, por meio de ação formal na OMC, neutralizasse a ameaça de congelamento de preços feita pelo Brasil, obtendo autorização para a produção de cópias mais baratas de seus remédios, capazes de competir com os genéricos brasileiros.

Tendo em vista os recursos financeiros doados por essa indústria às campanhas políticas do Partido Republicano, uma grande parte dos 
parlamentares e dos grupos ligados ao Poder Executivo colocaram-se favoráveis à adoção de políticas condizentes com seus interesses. "Primeiro eles servem como um grupo de pressão que, por meio de suas habilidades, contribuem para o fundo de campanha e mobilizam votos, formando diretamente as preferências do Executivo e do Legislativo; isso significa que as preferências dos grupos de interesses geralmente têm um significado similar às preferências políticas dos atores políticos" (Milner, 1997:60, tradução dos autores).

$\mathrm{O}$ win-set reivindicava aos negociadores estadunidenses que as leis de patentes fossem mantidas e que não fosse permitido ao Brasil produzir medicamentos utilizando-se do mecanismo da licença compulsória. Embora alguns grupos daquele país (principalmente ONGs ligadas aos direitos humanos e à saúde pública) e governos de alguns estados exigissem que as necessidades das populações deveriam prevalecer sobre o lucro, eles não tinham capacidade para transformar suas demandas em política pública.

Cabe ressaltar que a capacidade da indústria farmacêutica dos Estados Unidos de influenciar o governo deriva não apenas da sua contribuição substantiva para o Produto Interno Bruto - PIB, mas também porque, no ano de 2000, este setor doou mais de US\$ 26 milhões para a campanha presidencial do Partido Republicano. Este partido recebeu $69 \%$ de todas as doações a campanhas políticas realizadas por essa indústria; o atual presidente, George W. Bush, aparece como o político que recebeu a maior fatia delas (Center for Responsive Politics, 2000). Assim, é provável que esta seja a principal razão pela qual a indústria farmacêutica tem sido capaz de persuadir o governo e de ver suas demandas traduzidas em políticas.

“Embora finalmente os eleitores elejam líderes políticos (diretamente ou indiretamente), os interesses especiais podem ser uma ajuda enorme aos líderes. Podem produzir contribuições, votos, organização da campanha, a atenção dos meios, e assim por diante, que podem fazer a diferença entre ganhar e perder uma campanha" (Milner, 1997:35, tradução dos autores).

A pressão exercida pela indústria farmacêutica obteve resultados concretos quando a OMC estabeleceu um panel comunicando às autoridades brasileiras a queixa dos Estados Unidos, o que ocorreu no mesmo dia em que o Ministério da Saúde do Brasil decretou o congelamento dos preços dos medicamentos utilizados para o tratamento de 


\section{Gráfico 1}

Maiores Contribuidores da Indústria Farmacêutica e de Saúde

Ciclo eleitoral de 2000

Contribuições totais US\$26,707,861

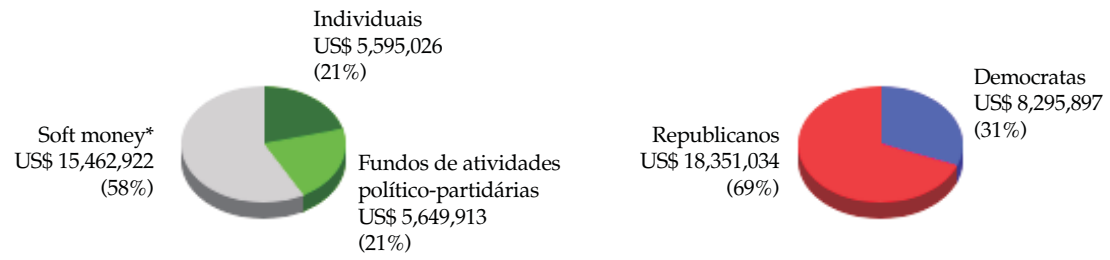

Fonte: Center for Responsive Politics, 2000 (tradução dos autores).

*Mecanismo da legislação eleitoral norte-americana utilizado por doadores de fundos de campanha que não querem declarar sua preferência pela vitória de um ou outro candidato.

HIV / AIDS. A medida do governo brasileiro visava forçar as indústrias detentoras de patentes a diminuir os seus preços; do contrário, seria colocado em prática o mecanismo da licença compulsória previsto no artigo 68 da Lei 9.279/96.

Segundo os negociadores estadunidenses, essa medida seria incompatível com as obrigações impostas pelo acordo TRIPS. Para eles, o artigo teria sido criado para obrigar que os detentores de patentes fabricassem suas invenções em território brasileiro (OMC, 2001a). Nesse sentido, o Brasil estaria discriminando produtos estadunidenses por meio de sua lei de propriedade intelectual, o que representaria violação do acordo TRIPS. Assim, os Estados Unidos sentiram-se compelidos a apresentar queixa formal na $\mathrm{OMC}$, requisitando o estabelecimento de um panel pelo OSC 6 . Em comunicado oficial do USTR, os Estados Unidos salientavam que as situações sob as quais as patentes podiam ser compulsoriamente licenciadas não estavam sendo questionadas e que a alegação brasileira de crise de saúde pública era considerada legítima. Para eles, a inconsistência com o acordo TRIPS residia no fato de haver, na lei brasileira, um "requerimento de produção local" (local manufacturing requirement), reiterando que a lei de patentes do Brasil fora formulada para obrigar os detentores de patentes a produzir suas invenções no país (OMC, 2001b) após um período de transição de três anos.

Em episódio ocorrido em 1996, ainda relacionado à tentativa do Poder Executivo dos Estados Unidos de proteger os interesses da indústria 
farmacêutica no Brasil, o país foi incluído na Super 301 Watch List. Trata-se de uma medida unilateral prevista pela legislação dos Estados Unidos que permite ao USTR investigar países suspeitos de violar interesses estadunidenses relacionados a patentes. Caso um país seja considerado culpado dessa acusação, ele pode ser colocado na Super 301 Watch List, ou, em casos mais graves, o USTR pode recomendar que o país seja retaliado. As retaliações ocorrem sob a forma de restrições às importações de um dado país, por meio de aumento dos impostos ou da aplicação de barreiras tarifárias e não tarifárias. Outro exemplo de canais de comunicação existentes entre a sociedade e o governo estadunidense é o fato de que cidadãos ou empresas privadas daquele país podem solicitar o início de uma investigação 301 junto ao USTR. Em outras palavras, existe nos Estados Unidos um canal institucionalizado através do qual a sociedade civil pode solicitar que o governo atue no âmbito internacional para preservar os interesses de atores domésticos. Dessa forma, o fato de que as indústrias podem interagir diretamente com o governo aumenta as possibilidades de um resultado satisfatório para os seus interesses.

O USTR é parte do Poder Executivo e suas atividades concentram-se na defesa das políticas relativas ao comércio internacional, buscando garantir os interesses comerciais estadunidenses onde quer que eles se encontrem. Os mecanismos de sua atuação são complexos e suas decisões são influenciadas por diversos fatores. O USTR tem sido bem-sucedido em disputas comerciais, e esta é uma das razões pelas quais os Estados Unidos são considerados um negociador internacional muito forte. A possibilidade de impor retaliações e sanções contra outros países, aliada ao enorme poder econômico do país, garante sucesso na maioria das disputas comerciais nas quais ele se envolve. Além disso, durante negociações bilaterais, algumas medidas são tomadas unilateralmente pelos Estados Unidos. Nessas negociações, e sem contar com a proteção das regras multilaterais da OMC, a maioria dos estados não têm como atingir resultados favoráveis, dado o desequilíbrio do poder de barganha (Bhala, 2001).

O Brasil não conta com uma agência governamental especializada em comércio internacional, o que dificulta a defesa, pelo Estado, dos interesses das coalizões domésticas no plano internacional. Da mesma forma, também a iniciativa privada brasileira não conta com mecanismos tão eficientes como o USTR. Impossibilitado de pautar-se por experiências anteriores, a cada novo contencioso, seja como demandante ou 
demandado, o Estado brasileiro vê-se obrigado a elaborar e sustentar estratégias singulares.

O presidente dos Estados Unidos é quem, em última instância, decide como lidar com problemas relativos ao comércio internacional, mas são tarefas do USTR, da Comissão de Comércio Internacional (International Trade Commission) e do Poder Legislativo identificar e investigar possíveis ameaças aos interesses comerciais do país. Normalmente, o presidente recebe relatórios formulados pelos grupos supramencionados a respeito de ameaças aos interesses comerciais estadunidenses, ou seja, sobre países que estão violando acordos comerciais ou adotando práticas comerciais consideradas injustas. Após receber estes relatórios, o presidente decide se e como os Estados Unidos irão agir em cada caso (idem). Nesse sentido, é necessário ressaltar que o chamado "interesse [comercial] dos Estados Unidos" será definido pelos jogos que ocorrem domesticamente, ligando portanto os âmbitos internacional e doméstico. Com base nas informações fornecidas por essas agências e pelo Congresso, o presidente formula sua política externa comercial.

É nesse momento que os grupos de interesse têm a oportunidade de pressionar o governo, sobretudo por meio de lobbies, para promover políticas que lhes sejam favoráveis. Dessa forma, os países podem ficar sujeitos a retaliações caso estejam empregando políticas que não satisfaçam uma determinada indústria estadunidense, uma vez que ela age domesticamente para influenciar o Estado a atuar na sociedade internacional.

Como afirmamos antes, isso ocorre devido ao fato de que, em grande medida, as indústrias financiam as campanhas políticas daquele país. A retirada de apoio de uma delas a um determinado candidato acarretaria a diminuição de suas doações para a próxima campanha, o que viria a frustrar as aspirações à eleição ou reeleição daquele candidato. Os políticos tendem a defender políticas que lhes garantirão apoio e/ou votos; em troca de seu apoio, as indústrias anseiam por políticas que lhes sejam favoráveis. "Os poderes executivos tentarão assim escolher as políticas que otimizam o estado da economia nacional e os interesses de seus grupos de apoio" (Milner, 1997:35, tradução dos autores). Algumas vezes, os políticos são praticamente "forçados" a defender uma preferência oposta à sua devido aos altos custos em que pode incorrer por optar por uma política que contrarie seus apoiadores e po- 
nha em risco seu cargo. Exemplo disso foi observado quando Bill Clinton, após deixar a Presidência - portanto livre dos constrangimentos eleitorais que poderiam ser impostos pela perda de apoiadores -, afirmou que os países em desenvolvimento deveriam ter o direito de fornecer medicamentos à sua população, ainda que através da licença compulsória. Agora, à frente da ONG William J. Clinton Presidential Foundation, engajada na luta contra HIV / AIDS, ele defende uma posição contrária àquela mantida durante seus dois mandatos (The Henry J. Kaiser Family Foundation, 2002; 2003a; 2003b) ${ }^{7}$. Esse posicionamento pode ser notado em discurso proferido em 12 de julho de 2002, em Barcelona, por ocasião do evento Action Against Aids: for the Global Good:

"Para as nações em desenvolvimento, isto significa concluir negociações com as empresas farmacêuticas alertando-as para o fato de que há outras opções de compra de genéricos por parte do Brasil, tais como da Índia. O que significa desenvolver planos para o cuidado e a prevenção baseado no que está funcionando em outros países. E, então, quando isso for feito, os países em desenvolvimento têm que determinar quanto podem pagar e emitir para o restante de nós a conta da diferença" (The Henry J. Kaiser Family Foundation, 2002, tradução dos autores).

Sob a ótica estadunidense, o acordo TRIPS apresenta muitas deficiências, como não garantir os direitos de detentores de patentes em todos os países signatários - permitindo que milhões de dólares em royalties que deveriam ser pagos a empresas estadunidenses sejam perdidos-e conceder um período muito longo para os países menos desenvolvidos adaptarem suas leis ao acordo (Bhala, 2001). Assuntos relacionados à Propriedade Intelectual estão no topo da lista de prioridades da diplomacia estadunidense; portanto, a essas questões será dada muita atenção, e os esforços do governo concentrar-se-ão em garantir os direitos dos detentores de patentes em todas as partes do mundo (idem).

\section{Estrutura Doméstica e Posição Negociadora Defensiva do Brasil}

O relativo sucesso brasileiro nesse contencioso deveu-se à combinação de diversos fatores. Em primeiro lugar, na OMC, os negociadores do Brasil utilizaram uma premissa de caráter humanitário: o bem público deve prevalecer sobre o lucro. Assim, legitimaram a sua estratégia de defesa e obtiveram a simpatia internacional da maioria dos países negociadores. Dentre eles, África do Sul - que sofre com a epidemia de HIV/AIDS e que, como o Brasil, não dispõe de recursos financeiros 
para garantir tratamento gratuito adequado a todos que necessitam -, Índia - país que conta com tecnologia avançada na produção de genéricos e medicamentos em geral, ocupando papel importante no comércio internacional do setor e interessada em vender seus genéricos -, Quênia, Moçambique, Zimbábue, Ruanda e outros países em desenvolvimento - interessados na transferência de tecnologia e na cooperação técnica internacional para o tratamento dos seus doentes de AIDS.

Por terem defendido o direito do Brasil e dos países em desenvolvimento ao acesso a medicamentos, a opinião pública internacional e as comunidades epistêmicas $^{8}$ (Haas, 1992) também foram essenciais para o sucesso nessa empreitada. Entre os atores principais, havia ONGs como Médicos sem Fronteiras, Health GAP, Oxfam e até mesmo a Organização das Nações Unidas - ONU, através do Programa Conjunto das Nações Unidas sobre HIV/AIDS - UNAIDS, a Organização Mundial de Saúde - OMS etc., envolvidas com os temas da saúde pública e dos direitos humanos, além de parcela considerável da sociedade civil estadunidense. Essas comunidades estavam convencidas de que o Brasil deveria ter o direito de fornecer medicamentos à sua população ainda que isso implicasse redução dos lucros da indústria farmacêutica.

O legado histórico-diplomático brasileiro traduzido no conceito de "autonomia pela integração" (Vigevani e Oliveira, 2003) foi fundamental para a obtenção do apoio internacional com essa dimensão. A demanda dos Estados Unidos desrespeitava tanto o direito internacional previsto pela OMC - cláusulas do acordo TRIPS que permitiam a licença compulsória em casos de emergência, também presentes na legislação norte-americana -, quanto os princípios de auto-determinação e não-intervenção dos povos, a mbos embutidos na ação internacional do Brasil. Além disso, era evidente que se tratava de uma verdadeira disputa entre Davi (Brasil) e Golias (EUA).

No plano doméstico, também houve amplo apoio à causa, a começar pelo governo e parte da sua burocracia: o presidente da República e os ministros da Saúde, da Fazenda e das Relações Exteriores. Aliados a eles, juntavam-se parlamentares filiados ao Partido da Social Democracia Brasileira - PSDB e à aliança governista, a indústria farmacêutica nacional produtora de genéricos, a população soropositiva - que geralmente se encontra organizada em ONGs, como o Grupo Pela Vidda, a Fundação Viva Cazuza, dentre outras, que muitas vezes atuam como 
parceiras domésticas de ONGs globais -, e também a opinião pública em geral, sobretudo o eleitor médio. No tocante às diferentes esferas do governo, podemos afirmar que cada uma delas tinha um interesse específico na questão. Contudo, evidências empíricas nos permitem apontar um de seus fios condutores: as ações do Poder Executivo na defesa da licença compulsória pareciam se prender, em grande medida e entre outras, a questões de natureza político-eleitoral.

O ministro da Saúde, José Serra, era presidenciável na ocasião, tendo sido confirmado posteriormente como candidato do PSDB com apoio do presidente da República Fernando Henrique Cardoso. Boa parte da sua campanha baseou-se na defesa dos genéricos e na promessa de que, se eleito, iria se empenhar na quebra das patentes (licença compulsória), necessária para fornecer tratamento de HIV / AIDS a um maior número de doentes ${ }^{9}$. O barateamento do tratamento desses doentes beneficiaria também o ministro da Fazenda, pois, sendo as despesas com o "coquetel" reduzidas, as verbas destinadas à saúde pública seriam suficientes para tratar, de maneira mais eficaz, um maior número de pacientes. Assim, de modo geral, essa política teria impactos positivos na melhora das finanças públicas.

Apesar de todo esse apoio, no entanto, o fator determinante da vitória brasileira nessa negociação deve-se ao papel exercido pelo MRE. A elaboração e execução da estratégia vencedora, em colaboração com agências estatais envolvidas na questão e parceiros internacionais e nacionais, sobretudo da sociedade civil, certamente constituíram uma experiência inédita levada a cabo pelo MRE. Através dela, o ministério demonstrou a importância do papel que pode ser desempenhado pela articulação entre as agências públicas e os atores privados na formulação e implementação de determinados acordos vinculados à política exterior do país na era da globalização. Na medida em que sua ação externa se pautava pela legitimidade democrática, essa experiência serviu também para amenizar as críticas de insulamento burocrático feitas à instituição, ampliando sua credibilidade junto à sociedade brasileira e internacional. Além disso, a negociação serviu de aprendizado para utilizar as estruturas globais de poder em prol dos interesses brasileiros e, o que é mais importante ainda, para auxiliar na construção de bens públicos globais, como a OMC, que devem ser utilizados por países menos favorecidos contra práticas comerciais desleais, sobretudo aquelas adotadas pelos países desenvolvidos. 
O que importa destacar é que, a partir da questão das patentes, e obviamente com claras pretensões eleitorais, José Serra conseguiu mobilizar em seu apoio atores domésticos e internacionais: a indústria farmacêutica e os laboratórios nacionais, as organizações da sociedade civil no Brasil e no exterior que auxiliam doentes de AIDS, parte da população sensível ao tema da saúde, parlamentares, organizações internacionais, parte da sociedade civil estadunidense e organizações de vários países.

Entretanto, para além da elaboração de uma excelente política pública de saúde, respeitada em todo o mundo, foi importante demonstrar a eficácia, a credibilidade e a legitimidade auferidas por uma estratégia de política externa que envolveu o apoio doméstico e internacional a uma ação do Estado brasileiro junto à OMC. Seu resultado foi bastante positivo, pois levou os negociadores dos Estados Unidos não apenas a optarem por retirar a queixa, recuando na sua posição intransigente de defesa dos direitos de propriedade intelectual da indústria farmacêutica norte-americana, mas também a negociar bilateralmente com o Brasil uma solução para o problema, como veremos adiante.

\section{A SOLUÇÃO DO CONTENCIOSO: A RETIRADA DA QUEIXA E A CRIAÇÃO DO MECANISMO CONSULTIVO BILATERAL}

A solução do conflito entre Estados Unidos e Brasil não percorreu todo o caminho da solução de controvérsias que existe no âmbito da OMC. Antes disso, os países chegaram a um acordo, e os Estados Unidos retiraram a queixa contra o Brasil. Esta solução foi possível graças à criação de um Sistema de Consultas estabelecido entre os dois países. Em 5 de julho de 2001, Estados Unidos e Brasil enviaram comunicado conjunto à OMC, no qual notificavam o OSC de que haviam alcançado uma solução satisfatória para o contencioso. No mesmo comunicado, os países informavam que havia sido criado um "Mecanismo Consultivo Bilateral", mas suas regras de funcionamento não foram explicitadas por nenhuma das partes. Anexa ao documento, foi enviada a troca de correspondência entre os governos brasileiro e estadunidense, na qual o Brasil propõe aos Estados Unidos a criação daquele Mecanismo e solicita que a queixa junto à OMC seja retirada. Em troca, o país comprometer-se-ia a consultar os Estados Unidos caso fosse necessário utilizar o artigo 68 e compulsoriamente licenciar alguma patente detida por empresa ou cidadão daquele país. Em resposta, os Estados Unidos concordaram em retirar a queixa, mas pediram que o Brasil se compro- 
metesse a não recorrer à OMC com respeito às seções 204 e 209 da Lei de Patentes dos Estados Unidos (OMC, 2001c).

A solicitação dos Estados Unidos permite inferir que as seções em questão realmente se assemelhavam aos artigos 68 e 71 da lei brasilei$\mathrm{ra}$, e portanto poderiam inviabilizar o argumento estadunidense. Logo, o país foi compelido a retirar a queixa antes que a demanda fosse julgada a favor do Brasil, mas, sobretudo, antes que fosse configurada sua derrota, já que esta abriria um precedente perigoso: outros países também poderiam impor retaliações aos Estados Unidos. Ou seja, uma derrota na OMC significaria abrir grandes brechas no acordo TRIPS, que seriam prejudiciais para outros setores da economia norte-americana. Além disso, segundo o USTR, o mecanismo criado conjuntamente entre Brasil e Estados Unidos foi mais efetivo e permitiu discussões mais amplas na tentativa de solucionar a questão em pauta (Office of The United States Trade Representative, 2001a; 2001b).

\section{A MUDANÇA DO CENÁRIO NO PÓS-11 DE SETEMBRO}

As discussões sobre a saúde pública, sobre a necessidade de rever o acordo TRIPS e sobre a forma de lidar com a propriedade intelectual, porém, não cessaram. Embora tenha sido retirada a queixa contra o Brasil, não havia sido encontrada uma solução para os problemas relacionados ao HIV / AIDS enfrentados pelos países em desenvolvimento. Por este motivo, continuaram ocorrendo encontros e reuniões em vários fóruns multilaterais, como a ONU, por exemplo, sempre na tentativa de estabelecer parâmetros a serem respeitados tanto por estados que necessitassem recorrer à licença compulsória ou à importação paralela, quanto por aqueles que se sentissem afetados por essas medidas. Ainda nesse sentido, entre 9 e 14 de novembro de 2001, foi realizada a Conferência Ministerial da OMC, em Doha, no Qatar, que, entre outros objetivos, procurou debater e esclarecer alguns pontos do acordo TRIPS que eram objeto de discórdia. Durante essa reunião, elaborou-se o documento intitulado "Declaration on the TRIPS Agreement and Public Health", que trata dos aspectos mais controversos do acordo.

A declaração reconhece os problemas de saúde pública enfrentados pelos países em desenvolvimento, sobretudo no tocante a epidemias como HIV / AIDS, tuberculose e malária, assinalando que a assinatura do acordo TRIPS não deveria impedir um país de promover políticas para garantir o acesso de sua população a medicamentos. Nela, garan- 
te-se o direito de cada membro determinar o que vem a ser uma situação de "emergência" e ficam definidas quais as situações em que - desde que respeitado o acordo TRIPS - a licença compulsória pode ser declarada. Ao mesmo tempo em que afirma a importância da saúde pública, a declaração enfatiza a necessidade de proteção à propriedade intelectual para que novos medicamentos sejam desenvolvidos (OMC, 2001c).

Esses argumentos, no entanto, dão margem a questões controversas, uma vez que o custo divulgado para o desenvolvimento de um medicamento nem sempre corresponde à realidade, já que nele são incluídos todos os gastos envolvidos, desde o início das pesquisas até o lançamento do produto no mercado. No entanto, ao longo das pesquisas, algumas vezes são descobertos outros medicamentos que podem ser comercializados e trazer lucros aos laboratórios - são os chamados "desdobramentos secundários". Isto é, muitos dos remédios novos produzidos baseiam-se em descobertas anteriores; portanto, não poderia ser possível contabilizar todo o custo do investimento anteriormente realizado em cada novo produto, como ocorre atualmente. Além disso, muitas vezes são empregados recursos públicos nas pesquisas, o que reduz o dispêndio de capital por parte dos laboratórios privados (Roffe, 2004). Ainda nesse sentido, os gastos com pesquisa e desenvolvimento (P\&D) são bastante reduzidos se comparados aos recursos utilizados para o marketing de novos medicamentos ou àqueles empregados em lobbies e doações a campanhas eleitorais. Além disso, segundo Roffe $(\mathrm{idem})^{10}$, os países em desenvolvimento não representam fatia significativa no consumo mundial de medicamentos.

O recuo na posição dos Estados Unidos quanto à proteção das patentes dos medicamentos decorreu, em grande medida, do fato de aquele país ter sido forçado a negociar a utilização do mecanismo da licença compulsória para reduzir o preço do antibiótico Ciprofloxacin, conhecido como Cipro, usado no tratamento do antraz. Conforme já mencionado, após os atentados terroristas de 11 de setembro de 2001, foi encontrado antraz em Nova York, Flórida e Washington D. C. (Office of The United States Trade Representative, 2001a; 2001b), o que gerou uma escalada na demanda pelo antibiótico; para atendê-la e diante da possibilidade de uma epidemia, o governo dos Estados Unidos resolveu aumentar seu estoque do medicamento. Nos Estados Unidos, a patente desse produto é detida pela Bayer e, em outubro de 2001, o preço da pílula de $500 \mathrm{mg}$ para o governo dos Estados Unidos era de US\$ 
1.83, enquanto a versão genérica do laboratório FDC, à venda na Índia, custava US\$ 0.06 (Singh, 2002).

Tabela 1

Preços Internacionais Selecionados do Ciprofloxacin

(Preços por pílula de $500 \mathrm{mg}$ em dólares americanos, outubro de 2001)

\begin{tabular}{lll}
\hline País & Companhia & Preço \\
\hline EUA & Bayer atacado & 4.67 \\
EUA & Bayer governo federal & 1.83 \\
Canadá & Bayer governo & 1.58 \\
Canadá & Apotex genérico/governo & 0.95 \\
Nova Zelândia & Bayer varejo & 1.29 \\
África do Sul & Bayer governo & 2.10 \\
Polônia & Bayer & 1.51 \\
Polônia & Polfa Grodzisk genérico & 0.29 \\
Índia & Bayer varejo & 0.13 \\
Índia & Blue Cross genérico/varejo & 0.10 \\
Índia & FDC genérico/varejo & 0.06 \\
\hline
\end{tabular}

Fonte: Singh, 2002.

As negociações entre o governo estadunidense e a Bayer ficaram a cargo de Tommy Thompson, secretário de Saúde e Serviços Humanos da administração Bush. Por conta delas, severas críticas recaíram sobre o governo estadunidense que, em vez de procurar abastecer seu mercado com medicamentos importados da Índia, ou mesmo autorizar laboratórios estadunidenses a produzi-los, optou por negociar junto à Bayer uma redução de preços, evitando ao máximo ter que declarar licença compulsória (Singh, 2002). Essa licença nunca chegou a ser decretada, pois o laboratório alemão concordou em reduzir os preços de maneira satisfatória. No entanto, ela poderia ter sido utilizada através do emprego da Section 1.498 do U. S. Code (EUA, 2003).

Segundo comunicado do USTR, se a licença compulsória fosse empregada, deveria ser paga uma compensação financeira ao detentor da patente, conforme estipulam o acordo TRIPS e a Section 1.498. Ainda no mesmo comunicado, o USTR afirmava que o antraz encontrado em território americano era perigoso o suficiente para detonar uma crise ou uma situação de emergência, o que justificaria - conforme o acordo TRIPS - a utilização, pelos Estados Unidos, da quebra da patente. Ao detentor da patente caberia buscar as compensações financeiras decor- 
rentes do seu uso de forma não-comercial. Finalizando o comunicado, o USTR ressaltava que essas flexibilidades não eram exclusivas dos Estados Unidos e que todos os membros da OMC podiam recorrer a elas (Office of The United States Trade Representative, 2001b).

Dessa forma, ainda que nunca tenham sido quebradas as patentes do Ciprofloxacin da Bayer, as declarações do USTR abriram uma espécie de precedente: após terem os próprios Estados Unidos declarado que, se necessário, recorreriam à licença compulsória, como poderiam coagir os demais estados a não fazê-lo em contextos idênticos?

Com efeito, na Conferência Ministerial de Doha, os Estados Unidos tiveram que defender uma maior liberalização da produção de medicamentos compulsoriamente licenciados. No entanto, a questão da importação paralela, utilizada por países que não têm capacidade de produção, foi deixada para ser discutida em reunião futura do Conselho do acordo TRIPS (OMC, 2001c). Nesse contexto, fica claro que a mudança no discurso e na prática estadunidenses também pode ser analisada na lógica do JDN. Primeiramente, é preciso atentar para o fato de que, após os ataques terroristas de 11 de setembro de 2001, a questão da quebra das patentes passou a despertar o interesse da população, já que ela poderia ser afetada por uma eventual epidemia de antraz. Em segundo lugar, é importante frisar que, apesar de representar a abertura de uma espécie de "precedente", a patente a ser quebrada naquela ocasião pertencia a um laboratório alemão, não implicando, portanto, redução nos lucros dos laboratórios estadunidenses. É necessário ressaltar também que, ainda assim, os interesses da indústria farmacêutica foram preservados pelo governo, pois caso sua primeira opção tivesse sido recorrer à licença compulsória, ela certamente acarretaria conseqüências para os laboratórios. Em terceiro lugar, aos representantes políticos interessava promover políticas que agradassem aos eleitores, e a movimentação que se seguiu ao 11 de setembro parecia indicar que aquele era um momento bastante propício para implementá-las.

Visando acomodar essa nova conjuntura, os Estados Unidos tiveram que modificar seu discurso e sua conduta nos fóruns multilaterais. Com efeito, durante negociações internacionais que tratavam da possibilidade de conferir maior elasticidade às patentes de medicamentos, em vez de tentar bloquear qualquer pleito no qual a licença com- 
pulsória fosse entendida como legítima, o país preferiu defender posição menos rígida.

Embora não agradasse à indústria farmacêutica estadunidense, essa estratégia serviria também a outro propósito, pois através de uma aparente maior liberalização no que se referia à propriedade intelectual, os Estados Unidos poderiam obter benefícios nas negociações de outros setores do comércio internacional. Assim, durante as negociações internacionais que se seguiriam, sobretudo aquelas relativas à Área de Livre Comércio das Américas - ALCA e às questões agrícolas no âmbito da OMC, o país poderia aproveitar a postura adotada quanto ao acordo TRIPS, alegando seu recuo que, afinal, teria representado uma concessão aos países em desenvolvimento. Estes, em contrapartida, deveriam adotar posturas mais flexíveis durante as negociações mencionadas. Ou seja, a estratégia de barganha também poderia ser empregada em negociações bilaterais.

Para o Brasil, porém, o recuo na posição estadunidense também foi de grande importância estratégica, já que em negociações futuras o país poderia agregar aos seus argumentos o precedente aberto pelos Estados Unidos, reforçando a importância e a validade da quebra de patentes. Com isso, poderia conseguir não só uma flexibilização ainda maior, mas também obter benefícios em negociações de outros setores.

“O Representante Comercial dos Estados Unidos, Robert Zoellick, abandonou, sem muita consulta, a indústria farmacêutica dos Estados Unidos, a Declaração sobre o Acordo TRIPS e Saúde Pública em Doha. A administração Bush agiu assim no contexto da política doméstica pós-11 de Setembro, no qual poderia ter que lançar mão de licenças compulsórias devido ao medo do antraz, sentindo uma forte necessidade em comprometer matérias da propriedade intelectual, prejudicando depois o lançamento de um novo círculo de comércio. Resumindo, quando as questões do TRIPS se tornam politizadas domesticamente nos Estados Unidos e na Europa, os países em desenvolvimento resistem mais para aderir e desenvolver políticas de propriedade intelectual em prol das suas próprias necessidades" (Shaffer, 2004:29, ênfases no original, tradução dos autores).

A dinâmica que se estabeleceu nos Estados Unidos no pós-11 de setembro exigiu da administração Bush um esforço conciliatório, já que o governo tentava equilibrar ao mesmo tempo tanto os interesses da indústria farmacêutica, quanto aqueles da sociedade civil. Isso porque, ao se 
preocuparem em solucionar o problema enfrentado por sua população, procurando garantir o acesso ao Cipro, os decision makers buscavam fazê-lo sem prejudicar os interesses da indústria farmacêutica norte-americana. Tratava-se, portanto, também de uma preocupação de cunho político-eleitoral, uma vez que, garantindo à sua população o acesso àquele medicamento, nas eleições seguintes o partido poderia obter um maior número de votos, já que o median-voter seria beneficiado por esta política - e era grande a mobilização social em torno do assunto. Simultaneamente, mantendo o respeito às patentes, o governo estaria garantindo o apoio da indústria farmacêutica, responsável por grande parte dos fundos doados para a campanha eleitoral do Partido Republicano.

Por fim, vale enfatizar que a estratégia do Brasil no contencioso das patentes provocou alterações significativas no acordo TRIPS, que acabaram favorecendo os interesses dos países em desenvolvimento. Em outras palavras, ao utilizar estruturas institucionais - especificamente a OMC, a estratégia adotada foi eficaz na medida em que alcançou resultados substantivos não apenas para o Brasil, mas também para outros países menos poderosos, em um contencioso que envolveu as principais potências da sociedade internacional contemporânea. Segundo Keohane (1992:179),

"Isso quer dizer que, para o parceiro mais fraco, a estratégia faz diferença. Políticos hábeis do país mais fraco podem ser capazes de encontrar aliados na sociedade e no governo dos Estados Unidos. [Nesse sentido,] [...] muitos governos têm sido ativos em articular lobbies nos Estados Unidos para influenciar a política comercial norte-americana".

Para Cepaluni (2004:107), "Em uma relação de interdependência assimétrica, os países mais fracos [devem procurar] perceber as contradições e as fraquezas das grandes potências, [buscar] alianças com 'atores transnacionais', [estabelecer] coalizões com nações com interesses semelhantes e [privilegiar] a resolução de conflitos em regimes internacionais", inclusive levando em consideração a possibilidade de alterá-los a seu favor.

\section{CONSIDERAÇÕES FINAIS}

Observar e compreender a interação dos atores que contribuíram para o estabelecimento da estrutura de preferência doméstica durante o processo de formulação das estratégias e das posições a serem adota- 
das pela diplomacia brasileira nas negociações internacionais - sobretudo na OMC - no tocante ao contencioso das patentes é essencial para o futuro do país por, pelo menos, dois motivos principais.

Em primeiro lugar, este estudo de caso fornece subsídios importantes para refletirmos sobre o desenho institucional mais adequado para que o Estado brasileiro possa ampliar sua capacidade de transformar as necessidades da sociedade civil do país em oportunidades internacionais. Para isso, é fundamental que o Brasil traduza, em prática doméstica, seu legado histórico-diplomático em prol da ampliação da democracia e do multilateralismo no mundo, através da construção de instituições políticas democráticas, eficazes na canalização das demandas dos grupos econômicos e sociais que têm interesses em jogo nas negociações comerciais internacionais contemporâneas.

Em outras palavras, as experiências de interação entre policy-makers e atores domésticos e internacionais acumuladas tanto pelo Estado brasileiro, na figura de sua diplomacia, quanto pela sociedade civil no contencioso na $\mathrm{OMC}$, permitem afirmar ser necessária a construção de instituições democráticas ex-ante e ex-post para a formulação da política externa do Brasil, cabendo ao MRE a exclusividade na tarefa de implementá-la. Certamente, um ponto de partida nesse sentido pode ser dado pela experiência - a ser aperfeiçoada - da relação institucional inaugurada durante o governo Fernando Henrique Cardoso, sobretudo no período de Celso Lafer à frente do MRE, entre a Coalizão Empresarial Brasileira - CEB e aquele ministério.

Roberto Teixeira da Costa corrobora essa idéia ao afirmar que "Sem um diálogo totalmente transparente entre setor público e privado, dificilmente haverá progresso nas negociações e não se conseguirá atingir objetivos que realmente atendam às necessidades do País". Ele reconhece que "[...] o papel dos negociadores não é fácil, pois sua capacidade de dialogar tem que ser mantida em duas frentes: a interna, na busca de um mínimo consenso, e a externa, obtendo os melhores termos para o nosso país". Mas defende a manutenção de "um canal amplo nessas conversações" (O Estado de S. Paulo, 4/7/2004).

Várias alternativas para o equacionamento dessa questão podem ser encontradas na experiência de outros países e servem como modelo para o Brasil construir instituições democráticas voltadas para o tratamento da política externa, mais especificamente no que se refere às negociações comerciais internacionais. Um exemplo paradigmático é o 
USTR - agência do Executivo para o comércio internacional - nos Estados Unidos, país onde as interações entre os grupos de interesse, o Legislativo e o Executivo são perceptíveis e dotadas de institucionalidade (Vigevani, 1995). Isso porque o USTR conta com a participação formal de representantes de empresas e associações privadas e de legisladores no seu processo de formulação de políticas (Noland, 1997; Vigevani, 1995). Além disso, as ações do USTR são acompanhadas de perto, quando não delimitadas, pelo Poder Legislativo. O Projeto de Lei no 189/2003 ${ }^{11}$, do senador Eduardo Suplicy (Partido dos Trabalhadores -PT/SP), visa criar instrumentos e mecanismos institucionais similares aos da Trade Promotion Authority - TPA nos Estados Unidos, e pode se constituir como alternativa viável para o Brasil.

Nos Estados Unidos, fica evidente que as relações domésticas entre grupos de interesse, parlamentares e membros do Executivo, reguladas por estruturas e instituições domésticas como o USTR e a TPA, funcionam como correias de transmissão entre os interesses domésticos norte-americanos e a sociedade internacional. Tendo em vista o poder dos Estados Unidos e sua relevância para a formação dos regimes internacionais, o USTR detém uma enorme capacidade de internacionalizar e legitimar as preferências domésticas no regime internacional de comércio - e de avalizá-as, por exemplo, junto à OMC. Como observamos no contencioso das patentes, o recuo dos Estados Unidos permitiu a flexibilização do acordo TRIPS e, portanto, o atendimento das demandas e das necessidades dos países em desenvolvimento ou menos desenvolvidos.

Em segundo lugar, a vitória do Brasil na OMC no contencioso das patentes só foi possível devido a três elementos principais: 1) escolha do multilateralismo na OMC no bojo da "autonomia pela integração" como estratégia de ação internacional; 2) o fato de ser uma demanda com forte apelo moral; e, por fim, 3) a interação democrática com atores domésticos e internacionais. A interconexão desses três elementos proporcionou credibilidade e legitimidade à estratégia de política externa brasileira durante as arbitragens nos panels e nas negociações comerciais internacionais na OMC. Por fim, vale ressaltar que o contencioso das patentes permitiu ao Brasil e a muitos aliados do G-20 flexibilizar o acordo TRIPS em prol das suas necessidades ${ }^{12}$.

Como vimos, a credibilidade e a legitimidade da estratégia brasileira só foram possíveis graças à interação democrática que se deu entre po- 
licy-makers e sociedade civil nacional e internacional em vários fóruns, sobretudo na OMC. Contudo, sem institucionalização, essa experiência pode ser relegada à memória nacional. Assim, para que o Brasil possa continuar se beneficiando de experiências como essa, é imperativo que esse padrão de relacionamento seja institucionalizado.

Na nossa opinião, a aprovação do Projeto de Lei 189/2003, já mencionado, é bem-vinda, pois ele será fundamental para subsidiar a participação do Brasil nas negociações comerciais internacionais que já estão em andamento. Ele possibilita ao Parlamento cumprir sua função em matéria de política externa, exercendo o papel de checks and balances, aprimorando o presidencialismo brasileiro e tornando-o, junto com suas burocracias, mais representativo e responsivo na formulação da política externa - o que de certo modo já ocorre com outras políticas públicas. Ao mesmo tempo, essa lei servirá para legitimar o negociador brasileiro diante dos seus parceiros internacionais ao evidenciar que as decisões e os interesses em jogo durante os acordos são colocados de forma transparente, distante do jogo intraburocrático e gerador de instabilidade institucional. É apenas com base nessas premissas que será possível garantir aos parceiros que aquilo que vier a ser acordado em uma negociação será rigorosamente cumprido pelo país. E isto parece não ocorrer na atualidade.

(Recebido para publicação em maio de 2005)

(Versão definitiva em setembro de 2006)

\section{NOTAS}

1. "Licença compulsória é a autorização concedida por um governo a um interessado que não seja o titular da patente de uma invenção para usar essa invenção sem o consentimento do titular da patente. [...] A licença compulsória age de forma a restringir o exercício desses direitos privados em favor do interesse público" (Roffe, 2004:59).

2. Dada a limitação de espaço, não será possível fazer essa análise neste artigo. Para uma discussão mais aprofundada, ver Oliveira (2005).

3. “Art. 62. Em caso de relevância e urgência, o Presidente da República poderá adotar medidas provisórias, com força de lei, devendo submetê-las de imediato ao Congresso Nacional, que, estando em recesso, será convocado extraordinariamente para se reunir no prazo de cinco dias. Parágrafo único. As medidas provisórias perderão efi- 


\section{Marcelo Fernandes de Oliveira e Fernanda Venceslau Moreno}

cácia, desde a edição, se não forem convertidas em lei no prazo de trinta dias, a partir de sua publicação, devendo o Congresso Nacional disciplinar as relações jurídicas delas decorrentes" (Constituição da República Federativa do Brasil, 1988; 2000, art. 62).

4. Para efeitos teóricos, neste artigo a classificação dos estados como "fortes" e "fracos" será baseada nas idéias desenvolvidas por Evangelista (1997), Risse-Kappen (1990) e Rogowski (1990). A passagem a seguir apresenta uma definição para estes conceitos, que deve ser observada: "O primeiro focou as instituições estatais e encontrou a expressão de maior proeminência no conceito de Estados 'fortes' e 'fracos'. Isso enfatiza o grau de centralização das instituições do governo e a capacidade do sistema político de controlar e acalmar a resistência doméstica. Estados fracos têm instituições políticas fragmentadas e estão mais abertos a pressões da sociedade e dos partidos políticos. Sua capacidade de se impor para a sociedade e extrair recursos dela é muito limitada. Estados fortes, ao contrário, são constituídos de instituições políticas centralizadas com fortes burocracias; são capazes de resistir às demandas públicas e buscar maior grau de autonomia vis-à-vis a sociedade" (Risse-Kappen, 1990:484, ênfases no original, tradução dos autores).

5. Borger (2003) afirma que a indústria farmacêutica, com grande margem de vantagem, é a mais lucrativa dos Estados Unidos, pois conta com uma taxa de retorno de investimento maior que duas vezes a média norte-americana.

6. "Em 30 de maio de 2000, os Estados Unidos requereram consultas ao governo do Brasil com base no Artigo 4 das Regras de Entendimento e Procedimento que disciplinam os mecanismos de disputas (DSU) e o artigo 64 do TRIPS [...] com relação a medida acima (WT/DS199/1). Os Estados Unidos e o Brasil abriram um período de consultas em Genebra em 29 de junho de 2000, o qual falhou, em dezembro de 2001, na resolução satisfatória para ambos os lados da disputa. Como resultado desse desacordo, os Estados Unidos requereram a instalação de um panel conforme o artigo 6 do Órgão de Solução de Controvérsias e o artigo 64 do Acordo TRIPS" (OMC, 2001a, tradução dos autores).

7. Em diversas ocasiões, o ex-presidente Bill Clinton deixou claro que atualmente sua opinião é diferente daquela que sustentava durante seus mandatos, em consonância com a lógica do dilema do governante. Exemplo disso pode ser observado na sua viagem à Índia, quando visitou o laboratório Ranbaxy, em Gurgaon. A visita, em novembro de 2003, teve o propósito de demonstrar apoio às companhias que fabricam anti-retrovirais genéricos a custos mais baixos, utilizados no tratamento de HIV / AIDS na Índia, em quatro países da África e em 12 países caribenhos. Naquela ocasião, Clinton declarou: "[A iniciativa] corta dois terços dos custos de remédios contra HIV / AIDS, tornando-os acessíveis a um número ampliado de pessoas, considerando a enorme dimensão desse problema" (Henry J. Kaiser Family Foundation, 2003a, tradução dos autores). Em outra ocasião, em 17 de junho de 2003, falando sobre a Clinton Foundation em Nova York, ele afirmou: "Nós não fizemos muito (com relação a HIV/AIDS) durante meu segundo mandato" (Henry J. Kaiser Family Foundation, 2003b, tradução dos autores).

8. Comunidades epistêmicas podem ser consideradas como "[...] canais através dos quais novas idéias circulam de sociedades a governos, bem como de país para país" (Haas, 1992:27). Ou ainda, “[...] uma rede de profissionais com perícia e competência reconhecidas em um domínio específico" (idem:3, tradução dos autores). 
9. Durante a disputa eleitoral pela prefeitura de São Paulo, em 2004, José Serra utilizou novamente esse episódio como base de seu marketing político.

10. “[...] convém notar que a participação dos países em desenvolvimento no mercado farmacêutico mundial é relativamente pequena. Por exemplo, em 2002, a África respondia por apenas 1,3\% dos lucros mundiais da indústria farmacêutica, enquanto que [sic] o sudeste asiático, a China e o subcontinente indiano juntos perfaziam meros $6,7 \%$. Os mercados dos países em desenvolvimento, de modo geral, quase não produzem impacto sobre as receitas da indústria farmacêutica" (Roffe, 2004:58).

11. Atual PL 4.291/04 (20/10/2004).

12. Para maiores esclarecimentos sobre esse assunto, ver Oliveira (2006).

\section{REFERÊNCIAS BIBLIOGRÁFICAS}

BHALA, Raj. (2001), International Trade Law: Theory and Practice. New York, Lexis Publishing.

BORGER, Julian. (2003), “USA: Pharmaceutical Industry Stalks the Corridors of Power”. The Guardian Unlimited. Disponível em http:/ / www.CorpWatch.org, acessado em 26/9/2003.

CONSTITUIÇÃO DAREPÚBLICAFEDERATIVADO BRASIL 1988 (2000). Brasília (DF).

CENTER FOR RESPONSIVE POLITICS. (2000), Influence Inc 2000: Top Industries: Pharmaceuticals/Health Products. Disponível em http:// www.opensecrets.org/ pubs/lobby00/topind01.asp, acessado em 26/9/2003.

CEPALUNI, Gabriel. (2004), O Contencioso Brasil x Estados Unidos no Setor Farmacêutico e a Licença Compulsória para Medicamentos contra o HIV/AIDS: Regimes Internacionais, Atores Transnacionais e Política Doméstica. Dissertação de Mestrado em Relações Internacionais, Programa San Tiago Dantas da Unesp, Unicamp e PUC/SP.

DE BRUNS NETO, Romeu. (2003), "O Lobby Sai do Armário". Revista Amanhã. Disponível em http:/ / www.revistaamanha.com.br, acessado em 12/10/2003.

ESTADOS UNIDOS DA AMÉRICA. (2003), U. S. Code. Disponível em http://www4.law.cornell.edu/uscode/, acessado em 15/12/2003.

EUA. BUREAU OF NATIONAL AFFAIRS. (2003), Pharmaceuticals: United States Drops Case Against Brazil Over HIV/AIDS Patent Law. Disponível em: <http://www.cptech.org/ip/health/c/brazil/bna06262001.html>, acessado em 26/9/2003.

EVANGELISTA, Matthew. (1997), “Domestic Structure and International Change", in M. W. Doyle e J. G. Ikenberry (orgs.), New Thinking in International Relations Theory. Boulder, Westview Press. 
HAAS, Peter M. (1992), “Introduction: Epistemic Communities and International Policy Coordination". International Organization, no 46, pp. 1-37.

KEOHANE, Robert O. (1992), "Soberania Estatal e Instituições Multilaterais: Respostas à Interdependência Assimétrica", in J. Álvaro Moisés (org.), O Futuro do Brasil: A América Latina e o Fim da Guerra Fria. São Paulo, Paz e Terra.

MARTIN, Lisa. (2000), Democratic Commitments: Legislature and International Cooperation. Princeton, Princeton University Press.

MILNER, Helen V. (1997), Interests, Institutions and Information. Domestic Politics and International Relations. New Jersey, Princeton University Press.

NOLAND, Marcus. (1997), “Chasing Phantoms: The Political Economy of USTR”. Institute for International Economics. Disponível em http:/ / www.iie.com/publications / wp/1997/97-1.htm, acessado em 3/5/2004.

O ESTADO DE S. PAULO. (2004), “Comunicação Truncada”. Disponível em <http:// www.estadao.com.br/ecolunistas/sonia/04/07/sonia040705.htm>, acessado em $27 / 7 / 2004$.

OFFICE OF THE UNITED STATES TRADE REPRESENTATIVE. (2001a), TRIPS and Health Emergencies. Disponível em http://www.ustr.gov/releases/2001/11/01-97.htm, acessado em 20/4/2004.

(2001b), United States and Brazil Agree to Use Newly Created Consultative Mechanism to Promote Cooperation on HIV / AIDS and Address WTO Patent Dispute. Washington D. C. Disponível em http://www.ita.doc.gov/td/icp/PRs/ WTO/WTOBrazil/AIDS010625.html, acessado em 12/1/2004.

OLIVEIRA, Marcelo Fernandes de. (2005), Negociações Comerciais Internacionais e Democracia: Formulação da Política Externa Brasileira nos Contenciosos das Patentes do Algodão e do Açúcar na OMC. Tese de Doutorado, Departamento de Ciência Política, Faculdade de Filosofia, Letras e Ciências Humanas, USP.

. (2006), “Estratégias Internacionais e Diálogo Sul-Sul no Governo Lula: Alianças Duradouras ou Coalizões Efêmeras?", in F. V. Oliveira (org.), Índia, Brasil e África do Sul: Perspectivas e Alianças. São Paulo, Editora Unesp.

ORGANIZAÇÃO MUNDIAL DO COMÉRCIO. (2001a), Brazil - Measures Affecting Patent Protection: Request for the Establishment of a Panel By the United States (WT/DS/199/3). Disponível em http://docsonline.wto.org/DDFDocuments/t/ WT/DS/199-3.doc, acessado em 15/1/2004.

. (2001b), Brazil - Measures Affecting Patent Protection: Notification of Mutually Agreed Solution (WT/DS199/4 G/L/454 IP/D/23/Add.1). Disponível em http://docsonline.wto.org/DDFDocuments/t/IP/d/23A1.doc, acessado em $15 / 1 / 2004$.

(2001c), Declaration on the TRIPS Agreement and Public Health. Disponível em http://docsonline.wto.org/DDFDocuments/t/WT/min01/DEC2.doc, acessado em $15 / 1 / 2004$.

PUTNAM, Robert. (1993), “Diplomacy and Domestic Politics: The Logic of Two-Level Games", in P. Evans, Harold K. Jacobson e R. D. Putnam (eds.), Double-Edged Diplomacy. Berkeley, University of California Press. 
RISSE-KAPPEN, Thomas. (1990), “Public Opinion, Domestic Structure, and Foreign Policy in Liberal Democracies". World Politics, vol. 43, pp.141-180.

ROFFE, Pedro. (2004), “Nota sobre Direitos de Propriedade Intelectual e Saúde Pública". Política Externa, vol. 12, o 3.

ROGOWSKI, Ronald. (1990), Commerce and Coalitions - How Trade Affects Domestic Political Alignments. Princeton, Princeton University Press.

SHAFFER, Gregory. (2004), Recognizing Public Goods in WTO Dispute Settlement: Who Participates? Who decides? The Case of TRIPS and Pharmaceutical Patent Protection. Manuscrito.

SINGH, Kavaljit. (2002), "Anthrax, Drug Transnationals, and TRIPS". Foreign Policy in Focus. Disponível em http://www.fpip.org/outside/commentary/2002/ 0204trips_body.html, acessado em 20/4/2004.

THE HENRY J. KAISER FAMILY FOUNDATION. (2002), “Clinton Urges Nations to Develop Plans to Halt HIV/AIDS, Says He Regrets Opposing Needle Exchange Programs While President". Kaiser Daily HIV/AIDS Report. Disponível em http://www.kaisernetwork.org/daily_reports / rep_index.cfm?DR_ID=12289, acessado em 20/4/2004.

. (2003a), "Clinton Foundation Plans To Treat 700,000 AIDS Patients in Africa, Caribbean Over Next Five Years". Kaiser Daily HIV/AIDS Report. Disponível em http: / / www.kaisernetwork.org/daily_reports/rep_index.cfm?hint=1\& DR_ID=18300, acessado em 20/4/2004.

. (2003b), "Former President Clinton Visits Generic Drug Maker Ranbaxy in India, Shows Support for Lower-Cost AIDS Drugs". Kaiser Daily HIV/AIDS Report. Disponível em http://www.kaisernetwork.org/daily_reports/rep_index.cfm?DR_ ID=20986, acessado em 20/4/2004.

VEIGA, João Paulo Cândia. (1999), As Políticas Domésticas e a Negociação Internacional: o caso da indústria automobilística no Mercosul. Tese de Doutorado, Departamento de Ciência Política, Universidade de São Paulo.

VIGEVANI, Tullo. (1995), O Contencioso Brasil x Estados Unidos da Informática: Uma Análise sobre Formulação da Política Exterior. São Paulo, Alfa-Ômega/Edusp.

e OLIVEIRA, Marcelo Fernandes. (2003), “Política Externa no Período FHC: A Busca de Autonomia pela Integração". Tempo Social, vol. 15, n² 2, pp. 31-61. 


\section{ABSTRACT \\ International Trade Negotiations and Democracy: The WTO Drug Patent Dispute between Brazil and the USA}

The aim of this article is to verify the analytical feasibility of Two-Level Game - TLG theory to analyze Brazil's action in the World Trade Organization WTO. We simultaneously analyze whether the enhancement of Brazilian democratic institutions in relation to foreign policy-making can help meet demands by interest groups and expand the technical quality of Brazilian diplomacy in international trade negotiations. We further verify whether this improvement can generate greater credibility and international legitimacy for Brazil's actions in the WTO, allowing the country to shape favorable international regimes for its interests. We develop this argument by analyzing Brazil's drug patent case against the USA in the WTO.

Key words: international trade negotiations; democracy; WTO; patents; interest groups

\section{RÉSUMÉ}

Négociations du Commerce International et Démocratie: Le Contentieux Brésil x EUA sur les Brevets Pharmaceutiques à l'Organisation Mondiale du Commerce

Dans cet article, on cherche la viabilité analytique du Jeu à Deux Niveaux JDN pour examiner la situation brésilienne dans l'Organisation Mondiale du Commerce - OMC. On cherche à voir, en même temps, si le perfectionnement des institutions démocratiques brésiliennes en ce qui concerne le processus de formulation de la politique extérieure sera capable d'améliorer la réponse aux demandes des groupes d'intérêt et d'élargir la compétence technique de la diplomatie brésilienne dans les négociations commerciales internationales. On cherche aussi à savoir si ce perfectionnement peut faire monter la crédibilité et la légitimité internationale des démarches brésiliennes au sein de l'OMC, dans le sens de tourner en leur faveur les régimes internationaux. Pour cela, on analyse le contentieux des brevets pharmaceutiques mené contre les États-Unis au sein de l'OMC.

Mots-clé: négociations commerciales internationales; démocratie; $\mathrm{OMC}$; brevets: groupes d'intérêt 